Article

\title{
Preparation and Evaluation of New Glycopeptides Obtained by Proteolysis from Corn Gluten Meal Followed by Transglutaminase-Induced Glycosylation with Glucosamine
}

\author{
Xiao-Lan Liu ${ }^{1,2}$, Chun-Li Song ${ }^{1}$, Jia-Peng Chen ${ }^{1}$, Xiang Liu ${ }^{1}$, Jian Ren ${ }^{1}$ and Xi-Qun Zheng ${ }^{1,2, *}$ \\ 1 Key Laboratory of Corn Deep Processing Theory and Technology of Heilongjiang Province, College of Food \\ and Bioengineering, Qiqihar University, Qiqihar 161006, China; liuxiaolan001@126.com (X.-L.L.); \\ songchunli@qqhru.edu.cn (C.-L.S.); xdldpgy@163.com (J.-P.C.); liuxiang2018001@163.com (X.L.); \\ renjian1970789@163.com (J.R.) \\ 2 College of Food, Heilongjiang Bayi Agricultural University, Daqing 163319, China \\ * Correspondence: zhengxiqun@126.com; Tel.: +86-452-2738341; Fax: +86-4522738341
}

Received: 31 March 2020; Accepted: 21 April 2020; Published: 1 May 2020

check for updates

\begin{abstract}
New glycopeptides were generated by proteolysis from corn gluten meal (CGM) followed by transglutaminase (TGase)-induced glycosylation with glucosamine (GlcN). The glycopeptides exhibited desirable antioxidant and intracellular ROS-scavenging properties. The amount of conjugated GlcN quantified by high-performance liquid chromatography (HPLC) was $23.0 \mathrm{~g} / \mathrm{kg}$ protein. The formed glycopeptides contained both glycosylated and glycation types, as demonstrated by the electrospray ionization time-of-flight mass spectrometry (ESI-TOF MS/MS). The glycopeptides exhibited scavenging capabilities against free radical diphenylpicrylhydrazyl (DPPH) and hydroxyl radicals by reducing their power. The potential protection of glycopeptides against ethanol-induced injury in LO2 cells was assessed In Vitro based on methyl thiazole tetrazolium (MTT) testing and intracellular reactive oxygen species (ROS) scavenging capacity, respectively. Glycopeptide cytoprotection was expressed in a dose-dependent manner, with the glycopeptides exhibiting good solubility ranging from $74.8 \%$ to $83.2 \%$ throughout a $\mathrm{pH}$ range of 2-10. Correspondingly, the glycopeptides showed good emulsifying activity $\left(36.0 \mathrm{~m}^{2} / \mathrm{g}\right.$ protein), emulsion stability $(74.9 \%)$, and low surface hydrophobicity (16.3). These results indicate that glycosylation of CGM significantly improved its biological and functional properties. Glycopeptides from CGM could be used as potential antioxidants as well as comprising a functional food ingredient.
\end{abstract}

Keywords: corn gluten meal; glycopeptides; property modification

\section{Introduction}

In 2019, China's yield of corn, one of the major cereal foods in the world, reached 260.77 million tons [1]. Approximately $14 \%$ of corn production is used to produce corn starch via a wet milling process [2], resulting in corn gluten meal (CGM) as the dominant co-product. CGM contains at least $60 \%(w / w)$ protein, including alcohol-soluble zein (68\%) and alkali-soluble glutelin (27\%) [3]. Zein and corn glutelin have unique amino acid compositions. Zein contains a high proportion of glutamic acid (21-26\%), leucine (20\%), proline (10\%) and alanine (10\%) [4], whereas corn glutelin is particularly rich in glutamic acid/glutamine (about 30\%). Leucine and proline play extremely important roles by exerting antioxidant effects, while glutamine promotes gastrointestinal tissue regeneration following toxic injury [5]. However, CGM has low solubility in aqueous systems, thereby limiting its application in the food industry, with almost all of CGM applied as feedstuff. Therefore, finding a solution to 
efficiently improve the solubility of CGM, reveal its activities, and broaden its applications in the food industry is a meaningful venture.

The glycosylation of proteins exhibits the potential to improve its biological and functional properties. Transglutaminase (TGase)-mediated (EC 2.3.2.13) glycosylation is a promising method, although traditional Maillard glycation has been widely used. TGase catalyzes the conjugation between saccharides and proteins (i.e., glycosylation), where proteins are used as acyl group donators and saccharides containing primary amines act as acyl group acceptors [6]. The conjugation of proteins to hydroxyl groups on saccharide molecules increases protein hydratability, correspondingly improving its solubility and allowing the biological properties of saccharides to be simultaneously incorporated into the protein. The improvement of pea legumin and wheat gliadin solubility at their isoelectric points was achieved via TGase-induced glycosylation [7]. The immunomodulation and inhibition of Escherichia coli via TGase-induced glycosylated caseinate hydrolysates [8] and cold water fish skin gelatin [9] were also observed, respectively.

The cross-linking of proteins and conjugation of saccharides occur simultaneously in TGase-induced glycosylation. TGase catalyzes the intermolecular and intramolecular protein cross-linking reactions between lysine and glutamine via acyl transfer, a process widely applied in the meat and dairy industries to improve gelation and protein texture [10], as well as varying the viscoelastic and rheological properties of the obtained products [11]. Controlling protein cross-linking is beneficial to saccharide conjugation. On one hand, reduced viscosity of the reaction system could benefit the reaction; however, a greater number of available reactive sites also increases saccharide conjugation. In this respect, CGM is a prospective substrate for TGase-induced glysosylation. The notable absence of lysine and the abundance of glutamine account for some intermolecular and intramolecular cross-linking reactions these molecules; correspondingly, TGase dominantly catalyzes glycosylation between saccharides and glutamine molecules.

The objective of this study was to produce glycopeptides from CGM and evaluate their biological activities. The moderate proteolysis of CGM was first conducted as a pretreatment to obtain intensive reaction sites, with the following glycosylation of CGM hydrolysates in the presence of TGase and glucosamine (GlcN) to prepare new glycopeptides. Electrospray ionization time-of-flight mass spectrometry (ESI-TOF MS/MS) was used to confirm the occurrence of the glycosylation/glycation reaction and intracellular ROS production and solubility was evaluated alongside the emulsification capabilities of the glycopeptides.

\section{Materials and Methods}

\subsection{Materials and Chemicals}

CGM was provided by Longfeng Corn Development Co., Ltd. (Suihua, Heilongiiang, China), with a total protein content of $61.3 \%$. GlcN was purchased from Sinopharm Chemical Reagent Co., Ltd. (Shanghai, China). TGase was purchased from Jiangsu Yiming Fine Chemical Industry Co., Ltd. (Qinxing, Jiangsu, China), with an activity of 1000 units (U) per gram (China). Alcalase $\left(6.28 \times 10^{5} \mathrm{U} / \mathrm{mL}\right)$ was a kind gift from Novo Nordisk (Bagsvaerd, Denmark). Pepsin (P-7000) and trypsin (T-7409) were purchased from Sigma. All other chemicals used were of analytical grade.

\subsection{CGM Purification}

CGM was purified from original CGM as per our previously reported method [12]. Briefly, CGM suspensions of $10 \%(w / v)$ in $\mathrm{pH} 6.0$ phosphate buffer were incubated with $\alpha$-amylase (30 $\mathrm{U} / \mathrm{g}$ of protein) at $60{ }^{\circ} \mathrm{C}$ for $2 \mathrm{~h}$. After boiling the solution to inactivate the enzyme, the mixture was filtered to remove starch hydrolysates. The residue was then washed with the same amount of water three times and centrifuged at $4500 \mathrm{r} / \mathrm{min}$ for $10 \mathrm{~min}$. The precipitate was collected and dried to obtain the starch-removed CGM. The obtained CGM powder was mixed with acetone at a ratio of 10:1 $(\mathrm{v} / \mathrm{w})$ and stirred for $45 \mathrm{~min}$. The mixture was then centrifuged at $4500 \mathrm{r} / \mathrm{min}$ for $10 \mathrm{~min}$ to collect the sediment, 
which was further processed twice using the same method and vacuum freeze-dried. The purified CGM was used to prepare the CGM hydrolysates.

\subsection{Preparation of CGM Hydrolysates}

CGM dispersions $(5 \%, w / v)$ were hydrolyzed by Alcalase at an enzyme to substrate (E:S) ratio of $0.5 \%(w / w)$, under gentle stirring at $60^{\circ} \mathrm{C}$ and $\mathrm{pH} 7.0$. The reaction $\mathrm{pH}$ was maintained by adding $2.0 \mathrm{~mol} / \mathrm{L} \mathrm{NaOH}$. The degree of hydrolysis (DH) of the CGM was determined by Adler-Nissen's method [13]. After hydrolysis, the reaction was terminated by boiling for $15 \mathrm{~min}$. The obtained hydrolysates were centrifuged at $4000 \mathrm{r} / \mathrm{min}$ for $10 \mathrm{~min}$, and the supernatant was collected, lyophilized and used for further analysis.

\subsection{Preparation of GlcN-CGM Hydrolysates}

The lyophilized CGM hydrolysates and GlcN were dissolved separately and mixed. TGase was then added to the above mixtures and incubated at a specific temperature and $\mathrm{pH}$ value in a water bath with a constant agitation. The content of conjugated GlcN was measured as an index of the reaction conditions. The following parameters were used in this reaction: $\mathrm{pH}$ at 7.0, 7.5 and 8.0; temperature at intervals of 5 from 35 to $55^{\circ} \mathrm{C}$; CGM hydrolysate concentrations of $3 \%, 4 \%$ and $4.4 \%(w / v)$; mole ratio of CGM hydrolysates and GlcN of 1:2, 1:3 and 1:4; E:S ratio at intervals of $5 \mathrm{U} / \mathrm{g}$ from 5 to $20 \mathrm{U} / \mathrm{g}$ protein; and reaction time at intervals of $0.5 \mathrm{~h}$ from 1 to $4 \mathrm{~h}$. The reaction was terminated by heating at $85^{\circ} \mathrm{C}$ for $10 \mathrm{~min}$. The obtained products were conducted with dialysis treatment against distilled water and the retentates (GlcN-CGM hydrolysates) were collected, lyophilized and stored at $-18{ }^{\circ} \mathrm{C}$. Cross-linked CGM hydrolysates were also prepared under the same conditions without the addition of GlcN. CGM, CGM hydrolysates and cross-linked CGM hydrolysates were used as controls.

In addition, in order to minimize any interference in the ESI-TOF MS/MS analysis, pure TGase from guinea pig liver tissue (Sigma-Aldrich) was used during preparation.

\subsection{HPLC Analyses}

Conjugated GlcN was released from the prepared GlcN-CGM hydrolysates by $\mathrm{HCl}$ hydrolysis [14], and the glucosamine was reacted with anthranilic acid-derivatizing reagent. The stable derivative was then measured via the ultraviolet detection of HPLC analysis [15]. The analysis was performed on a Hitachi HPLC 2130 (Tokyo, Japan), equipped with an L-2400 UV-detector with an applied detection wavelength of $230 \mathrm{~nm}$. A C 18 column ( $50 \mathrm{~mm} \times 4.6 \mathrm{~mm}$, Waters Corporation, Milford, MA, USA) was used to analyze the glucosamine derivative with a gradient elution program. Solvent A consisted of $0.4 \%$-butylamine, $0.5 \%$ phosphoric acid and $1.0 \%$ tetrahydrofuran in water. Solvent $B$ consisted of equal parts solvent $\mathrm{A}$ and acetonitrile. The elution was performed at $4 \% \mathrm{~B}$ for $30 \mathrm{~min}$, followed by a linear increase to $100 \% \mathrm{~B}$ at $45 \mathrm{~min}$ [15]. The amount of conjugated GlcN was calculated using a regression equation obtained from a GlcN standard solution, expressed as $\mathrm{g} / \mathrm{kg}$ protein.

\subsection{Fourier-Transform Infrared (FTIR) Spectra}

For FTIR analysis, the samples (CGM hydrolysate, cross-linked CGM hydrolysate and GlcN-CGM hydrolysate) were mixed with $\mathrm{KBr}$ at a ratio of 1:50 (w/w), with $40 \mathrm{mg}$ of the mixture prepared in $\mathrm{KBr}$ discs under dry air at room temperature. All FTIR spectra were obtained using a Spectrum One FTIR spectrometer (Perkin Elmer Inc., Norwalk, CT, USA) by scanning from 4000 to $400 \mathrm{~cm}^{-1}$ at a resolution of $1 \mathrm{~cm}^{-1}$. A total of 32 scans were used. 


\subsection{ESI-TOF MS/MS Analysis Conditions}

\subsubsection{LC Chromatographic Conditions}

The fraction separation of two CGM hydrolysates was carried out using an ACQUITY UPLC (Rsystem (Waters, Milford, MA, USA) with a BEH (Ethylene Bridged Hybrid) column (particle size: $100 \mathrm{~mm} \times 1.7 \mu \mathrm{m})$. The mobile phases $A$ and $B$ were acetonitrile and $0.1 \%$ formic acid in water, respectively. The flow gradient was $0-10 \mathrm{~min}, 15-50 \%$ A, curve 6 , and $10-12 \mathrm{~min}, 50-100 \%$ A, curve 1 with a flow rate of $1 \mathrm{~mL} / \mathrm{min}$.

\subsubsection{Mass Conditions}

The RP-HPLC system was connected to a Waters XEVO G2 Q-Tof MS equipped with an ESI interface. The desolvation temperature and desolvation gas flow of the ESI interface were $300{ }^{\circ} \mathrm{C}$ and $600 \mathrm{~L} / \mathrm{h}$, respectively. Positive ion intensities ranging between 100-1200 m/z were recorded using full-scan MS. Leucine-enkephalin was used as the mass spectrometry standard.

\subsection{Evaluation of Antioxidant Properties of Glcn-CGM Hydrolysates and their In Vitro Digestive Products}

The antioxidant properties of four CGM samples (CGM, CGM hydrolysates, cross-linked CGM hydrolysates and GlcN-CGM hydrolysates samples) and their In Vitro digestive products (pepsin and pepsin-trypsin digestions) were determined using our previously reported methods [16] with minor modifications. Four different methods (In Vitro), namely diphenylpicrylhydrazyl (DPPH) radical-scavenging ability, reducing power, hydroxyl radical-scavenging ability and $\mathrm{Fe}^{2+}$-chelating activity, were used to analyze the antioxidant properties of the samples.

Four CGM samples were hydrolyzed by pepsin and pepsin-trypsin to indicate In Vitro digestibility according to the methods of Marciniak-Darmochwal and Kostyra [17] and Tang, Sun, Yin and Ma [18], respectively. Briefly, for one-step hydrolysis, $2 \mathrm{mg}$ of pepsin was added to $10 \mathrm{~mL}$ of protein dispersion $(1 \%, w / v, \mathrm{pH} 2.0)$ and incubated at $37^{\circ} \mathrm{C}$ for $2 \mathrm{~h}$. The supernatants were collected by centrifugation at $10,000 \times g$ for $20 \mathrm{~min}$. For two-step hydrolysis, $10 \mathrm{~mL}$ of protein dispersion $(1 \%, w / v, \mathrm{pH} 2.0)$ was subjected to incubation for $1 \mathrm{~h}$ at $37^{\circ} \mathrm{C}$ with pepsin, as mentioned above. The mixture was then heated at $90{ }^{\circ} \mathrm{C}$ for $5 \mathrm{~min}$ and the sample was lyophilized. The reconstituted solution (10 mL, pH 8.0) was subjected to trypsin hydrolysis $(6 \mathrm{mg})$ at $37^{\circ} \mathrm{C}$ for $1 \mathrm{~h}$. Finally, the supernatants were collected by centrifugation at $10,000 \times \mathrm{g}$ for $20 \mathrm{~min}$ and used to analyze the antioxidant properties of the samples.

\subsection{MTT Method for Antitoxicity Assay}

Methyl thiazole tetrazolium (MTT) testing was used to evaluate the CGM peptide samples' cytotoxicity in LO2 cells based on the work by Choe et al. [19]. LO2 cell mixtures were seeded into 96-well plates with a density of $1 \times 10^{5}$ cells per well and allowed to attach at $37^{\circ} \mathrm{C}$ for $6 \mathrm{~h}$. Thereafter, the cells were cultured in the presence of various concentrations of peptide samples $(0.005-1.0 \mathrm{mg} / \mathrm{mL})$ for another $24 \mathrm{~h}$. The wells were then washed in phosphate buffer and then incubated with MTT at a final concentration of $0.5 \mathrm{mg} / \mathrm{mL}$ for an additional $4 \mathrm{~h}$. The remaining MTT solution was then carefully removed. Finally, $150 \mu \mathrm{L}$ of dimethyl sulphoxide (DMSO) was added to dissolve the formed formazan. The absorbance at $570 \mathrm{~nm}$ was monitored by an EnSpire microplate reader (Perkin Elmer, Waltham MA, USA). Control cells were used in each assay. The cell viability was calculated as Cell viability $(\%)=\mathrm{OD}_{\text {test }} / \mathrm{OD}_{\text {control }} \times 100$.

\subsection{Detection of Intracellular ROS Production}

The effect of GlcN-CGM hydrolysate addition on intracellular ROS production was measured using a $2^{\prime}, 7^{\prime}$-dichlorofluorescein diacetate (DCFH-DA) probe as an indicator, following the method of Vieira, da Silva, Carmo and Ferreira [20]. LO2 cell samples of $100 \mathrm{uL}$ were seeded into 96-well plates with a density of $1 \times 10^{5}$ cells per $\mathrm{mL}$ when they reached the logarithmic growth phase and 
allowed to attach at $37^{\circ} \mathrm{C}$ for $6 \mathrm{~h}$. The cells were then incubated for $4 \mathrm{~h}$ with different concentrations of peptides $(0.05-2 \mathrm{mg} / \mathrm{mL})$. Following the pretreatment with peptides, the cells were washed twice with PBS and incubated with the same volume of 3\% (v/v) ethanol for $24 \mathrm{~h}$. After that, the cells were washed twice with PBS and incubated in the presence of DCFH-DA for $20 \mathrm{~min}$, followed by another two washes with PBS and the careful removal of the extracellular probe (DCFH-DA). The cells trapped the fluorescent dye (DCF) inside, allowing for the monitoring of the fluorescence values using an EnSpire microplate reader (Perkin Elmer, Waltham MA, USA) by excitation at $485 \mathrm{~nm}$ and emission at $530 \mathrm{~nm}$. Two controls, i.e., cells treated with medium or 3\% (v/v) ethanol only, were also included. The $2^{\prime}, 7^{\prime}$-dichlorofluorescein (DCF) fluorescein intensity values at $\mathrm{Ex} / \mathrm{Em} 485 / 538 \mathrm{~nm}$ were measured. ROS (\%) was expressed relative to the maximum ROS levels of the negative control, i.e., the cells treated with medium only.

\subsection{Solubility}

Lyophilized samples were dispersed in various buffers, including citrate-phosphate at $\mathrm{pH}$ 2.8-7.0, barbital sodium chlorhydric acid buffer at $\mathrm{pH}$ 7.0-9.5, $\mathrm{Na}_{2} \mathrm{CO}_{3} / \mathrm{NaHCO}_{3}$ at $\mathrm{pH} 9.5-10.4$ and $\mathrm{Na}_{2} \mathrm{HPO}_{4} / \mathrm{NaOH}$ at $\mathrm{pH} 11.8$. The four CGM samples $(2 \mathrm{mg} / \mathrm{mL})$ were centrifuged $(8000 \times g)$ for 20 min after overnight rehydration at $4{ }^{\circ} \mathrm{C}$, and the supernatant was collected to determine the protein content. The nitrogen solubility was expressed as a percentage of the protein content of the supernatant according to the initial total protein content of the dispersion [21].

\subsection{Emulsifying Property}

The emulsifying activity index (EAI) and the emulsifying stability index (ESI) of the four CGM samples were determined using a turbidimetric method by Pearce and Kinsella [22]. Emulsions were prepared by mixing soybean oil with $1 \mathrm{mg} / \mathrm{mL}$ protein dispersion $(25 \mathrm{~mL}: 75 \mathrm{~mL})$, followed by homogenization for 1 min using a Model DS-1 high-speed homogenizer (Shanghai Specimen and Model Factory, Shanghai, China). Samples containing $10 \mu \mathrm{L}$ of the prepared emulsion were mixed adequately with $5 \mathrm{~mL}$ of phosphate buffer $(0.1 \mathrm{~mol} / \mathrm{L}$, $\mathrm{pH} 7.0)$ containing $1 \mathrm{mg} / \mathrm{mL}$ sodium dodecyl sulphate. The absorbance of the emulsions was recorded at $500 \mathrm{~nm}$ using an UV 752 spectrophotometer (Xinmao Instrument Co. Ltd., Shanghai, China). The EAI and ESI were calculated as follows (Equations (1) and (2)):

$$
\begin{gathered}
\operatorname{EAI}\left(\mathrm{m}^{2} / \mathrm{g}\right)=\frac{2 \times 2.303 \times \mathrm{A}_{0} \times \text { dilution }}{\mathrm{C} \times(1-\varphi) \times 10^{4}} \\
\text { ESI } \%)=\frac{\mathrm{A}_{10}}{\mathrm{~A}_{0}} \times 100
\end{gathered}
$$

where $C$ is the concentration of the aqueous phase protein $(10 \mathrm{~kg} / \mathrm{L}), \varphi$ is the volumetric fraction of oil and $\mathrm{A}_{0}$ and $\mathrm{A}_{10}$ are the absorbance values of the initial emulsion formation after the maintenance of a static condition for $10 \mathrm{~min}$, respectively.

\subsection{Surface Hydrophobicity}

Surface hydrophobicity was determined on the basis of the procedures described by Hayakawa and Nakai [23]. Four CGM samples dispersed in sodium phosphate buffer (10 mmol/L, pH 7.0) were centrifuged at $10,000 \times g$ for $15 \mathrm{~min}$ and the supernatants were collected. A total of $4 \mathrm{~mL}$ of obtained supernatant was mixed with $20 \mu \mathrm{L}$ of 1-anilino-8-naphthalene-sulphonate (ANS, $8.0 \mathrm{mmol} / \mathrm{L}$ ). The fluorescence intensities of the mixtures were recorded at $390 \mathrm{~nm}$ (excitation wavelength) and $470 \mathrm{~nm}$ (emission wavelength) at a range of protein concentrations, from 0.025 to $0.4 \mathrm{mg} / \mathrm{mL}$. The initial slope of the fluorescence intensity versus the protein concentration plot was regressed and expressed as an index of the protein surface hydrophobicity. 


\subsection{Statistical Analysis}

All data were expressed as means or means \pm standard deviations from three independent experiments. Differences between the means of multiple groups were analyzed via post-hoc testing of one-way analysis of variance (ANOVA), alongside Duncan's multiple range tests. SPSS 13.0 software (SPSS Inc., Chicago, IL, USA) was used to analyze the data.

\section{Results and Discussion}

\subsection{Establishment of Glycosylation Reaction Conditions}

In order to obtain intensive reaction sites during CGM glycosylation, the moderate proteolysis of CGM was adopted as a technical pretreatment step before TGase-induced CGM glycosylation. Insoluble CGM was first subjected to hydrolyzation by Alcalase at an E:S of $0.5 w / w$. The soluble supernatant was collected when the DH of CGM reached 5\% in order to obtain more reaction sites in the following TGase-induced glycosylation.

To achieve a high degree of glycosylation, the reaction time, $\mathrm{pH}$, temperature, E:S ratio, CGM hydrolysate concentration, and the mole ratios of the CGM hydrolysate and GlcN were optimized. The results show that the optimal $\mathrm{pH}$ was 7.5 , which fell in the range provided by the manufacturer. The optimum reaction temperature, the ratio of E:S and CGM hydrolysate concentration were $45^{\circ} \mathrm{C}$, $10 \mathrm{U} / \mathrm{g}$ protein and $4 \%(w / v)$, respectively. As more intensive conjugation was observed at higher concentrations of acyl acceptors (GlcN), a technologically reasonable mole ratio of CGM hydrolysate to GlcN (1:3) was applied. Under the above conditions, the optimal reaction time was $3 \mathrm{~h}$. Under the optimized conditions, the amount of GlcN in the GlcN-CGM hydrolysates, quantified by HPLC, was $23.0 \mathrm{~g} / \mathrm{kg}$. This value was higher than that of the glycosylated soybean protein ( $2.62 \mathrm{~g} / \mathrm{kg}$ SPI) [24] and casein (10.3 g/ $/ \mathrm{kg}$ casein) [25], which were catalyzed by TGase. The greater amount of glutamine in the CGM hydrolysate substrate provided more available reactive sites for GlcN conjugation during the reaction.

\subsection{Evaluation of Glycoconjugation}

\subsubsection{HPLC}

HPLC was used to analyze the modified CGM hydrolysates to qualify the amount of conjugated GlcN. The retention times of the standard GlcN were 9.60 and $10.66 \mathrm{~min}$, which, respectively, corresponded to AA-GlcN and its epimer (data not shown). As expected, the same phenomenon was also observed in the GlcN-CGM hydrolysates but not in CGM hydrolysates, potentially giving preliminary evidence of GlcN conjugation.

\subsubsection{FTIR}

The FTIR absorbance spectra of the samples provide information about unique chemical bonds, so the FTIR analytical technique was used here to identify different components. FTIR spectroscopy was also used to show changes in the CGM hydrolysates side-chains after treatment with TGase and $\mathrm{GlcN}$; these results are shown in Figure 1. Typical -C-O stretching and $-\mathrm{OH}$ deformation vibrations occurred at 1050-1150 $\mathrm{cm}^{-1}$. Intense deformation vibrations were observed when the hydroxyl groups of the saccharide molecules were conjugated into proteins. Compared with the CGM hydrolysates, the absorbance at $1025 \mathrm{~cm}^{-1}$ of the GlcN-CGM hydrolysates was significantly strengthened, as expected. These results indicate that the GlcN-CGM hydrolysates contained more -OH groups via covalent bonds, meaning that the modified products contained groups from GlcN. When free saccharides were removed, the glycopeptides were regarded as obtained via TGase-induced glycosylation. A similar phenomenon was also observed in soy protein isolate grafts obtained by glycation [26]. 


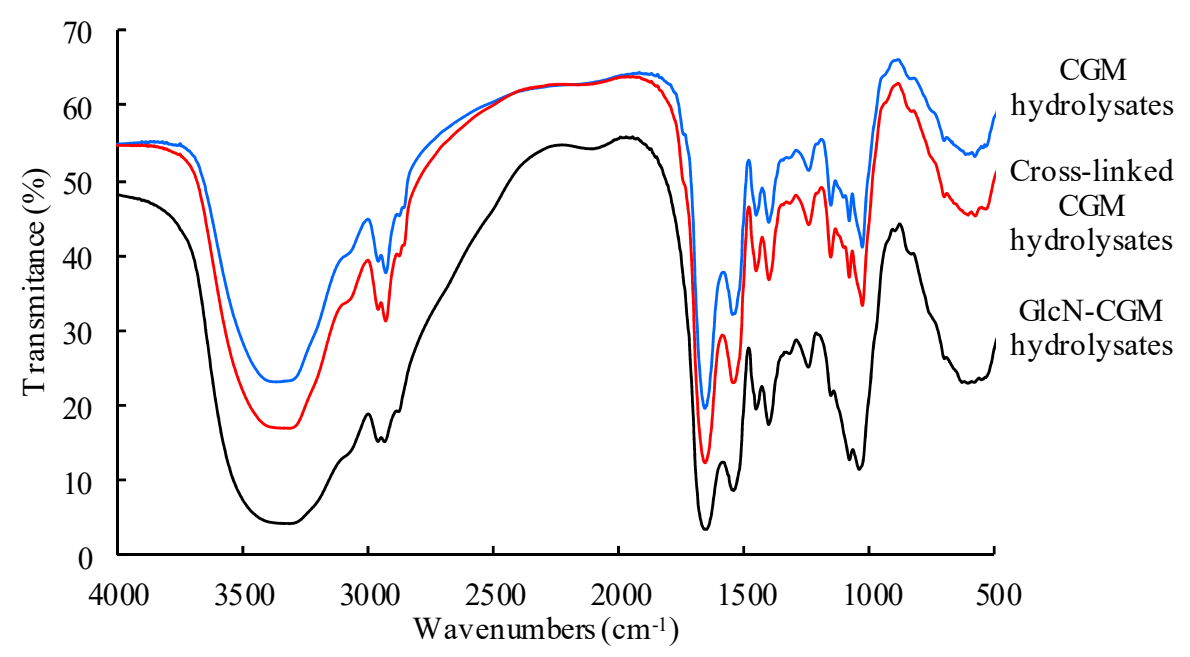

Figure 1. Fourier-transform infrared (FTIR) spectra in KBr pellets of corn gluten meal (CGM) hydrolysates, cross-linked CGM hydrolysates and glucosamine (GlcN)-CGM hydrolysates.

\subsubsection{ESI-TOF MS/MS}

Electrospray ionization mass spectrometry (ESI-MS/MS) analysis is a useful tool to qualitatively describe glycopeptides carrying $\mathrm{N}$-acetyl glucosamine on a specific amino acid. Depending on the mechanism of the TGase-catalyzed glycosylation reaction, the primary amino groups of the glutamine residues in CGM hydrolysate chains function as acyl donors, whereas GlcN acts as an acyl acceptor. Conjugating GlcN to glutamine residues is accompanied by $\mathrm{NH}_{3}$ release. The presence of glycosylation in peptides (glycopeptides) was evaluated by a mass shift of $162 \mathrm{Da}$ (GlcN: $179 \mathrm{Da} ; \mathrm{NH}_{3}$ : $17 \mathrm{Da}$ ) in comparison with the original peptide. Seven glycopeptides with high intensity were found from the GlcN-CGM hydrolysation (Figure 2a), with molecular weights of 651.4, 779.4, 794.4, 813.4, 890.4, 907.4 and 1060.6 Da. These results show that GlcN was conjugated into CGM hydrolysates. TGase-induced glycosylation of fish skin gelatin hydrolysates in the presence of GlcN was also confirmed by another MS method (MALDI-TOF-MS) [9].

Heating the mixture was used to deactivate the TGase during preparation. The possibility of traditional Maillard-type glycation between GlcN and CGM hydrolysates was considered. The mass shift of $161 \mathrm{Da}\left(\mathrm{GlcN}\right.$ : $179 \mathrm{Da} ; \mathrm{H}_{2} \mathrm{O}: 18 \mathrm{Da}$ ) was also taken into account. Six glycopeptides with the following molecular weights were produced through glycation: 650.4, 684.4, 778.4, 889.4, 891.4 and 906.4 Da (Figure 2b). ESI-MS/MS analysis indicated that GlcN was conjugated into CGM hydrolysates via TGase- and Maillard-type reactions based on our glycopeptide preparation process. 

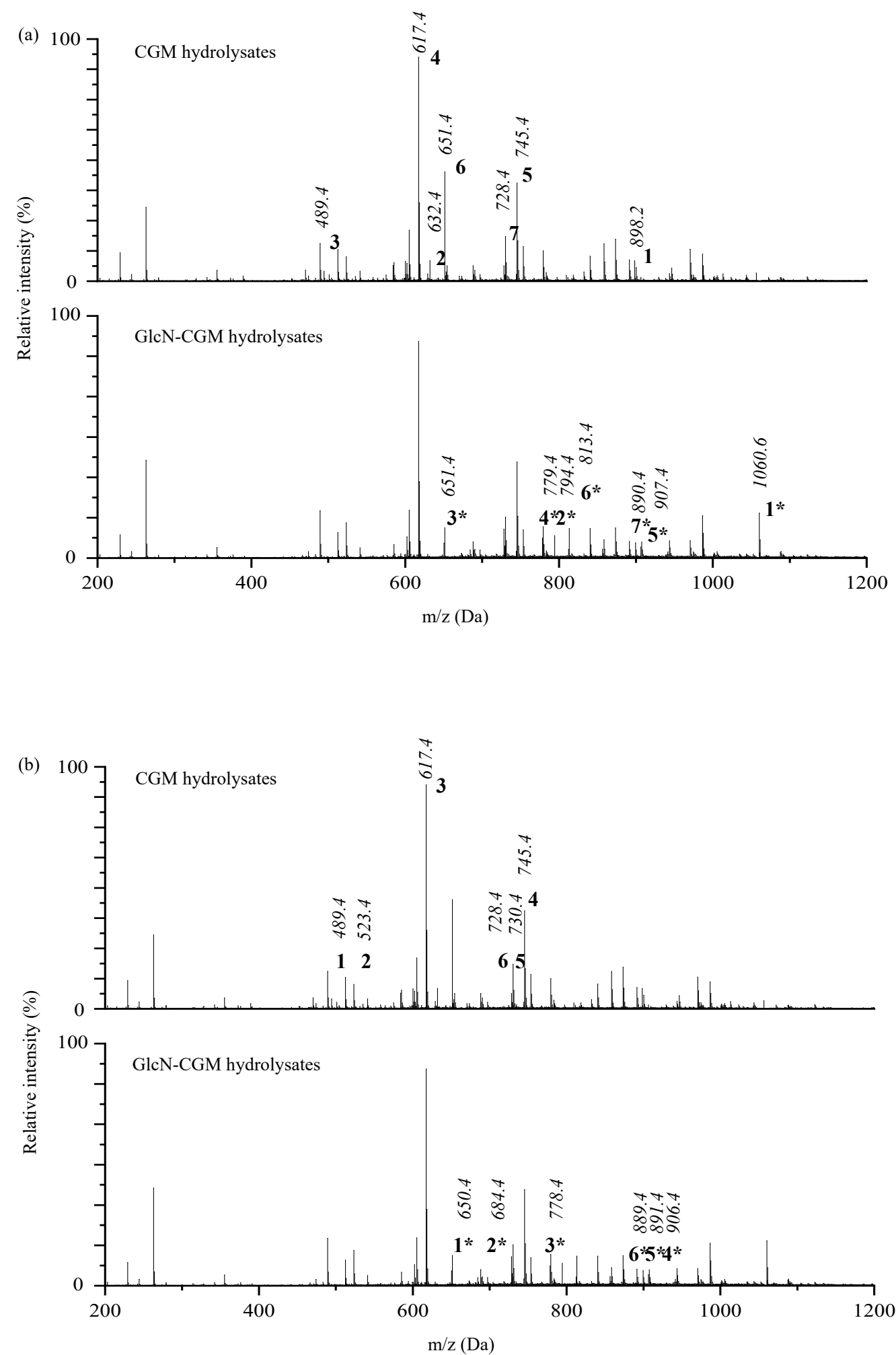

Figure 2. ESI-MS/MS spectra of CGM hydrolysates (a) and CGM hydrolysates conjugated with GlcN by TGase at $37^{\circ} \mathrm{C}(\mathbf{b})$. GlcN-CGM hydrolysates and natural CGM hydrolysates are indicated with the same number. 


\subsection{Biological Properties of Glycopeptides}

3.3.1. Antioxidant Properties In Vitro of the Prepared Glcn-CGM Hydrolysates and its Digestion Products

DPPH is a typical method used to evaluate the antioxidant activities of compounds In Vitro, depending on a quantitative relationship between the degree of DPPH fading and the number of proton donators [27]. GlcN-CGM hydrolysates exhibited the highest scavenging activity against DPPH $(77.5 \%)$ at $2 \mathrm{mg} / \mathrm{mL}$, which was higher than the CGM hydrolysates $(72.5 \%)$ and about three times greater than CGM $(24.86 \%)$ (Figure 3a). The conjugated saccharide moiety and the hydrolysis treatment caused more electrons to be donated. These electrons reacted with free radicals, thereby preventing the radical chain reaction. Similar results were also reported regarding the radical-scavenging ability of DPPH due to the increase of glycated gluten hydrolysates after the treatment of GlcN by TGase [28]. High DPPH radical-scavenging activities were also observed when the CGM hydrolysates and their GlcN-conjugated products were hydrolyzed by pepsin or pepsin-trypsin (Figure 3a), suggesting that GlcN conjugation with CGM hydrolysates enhanced radical-scavenging activity.
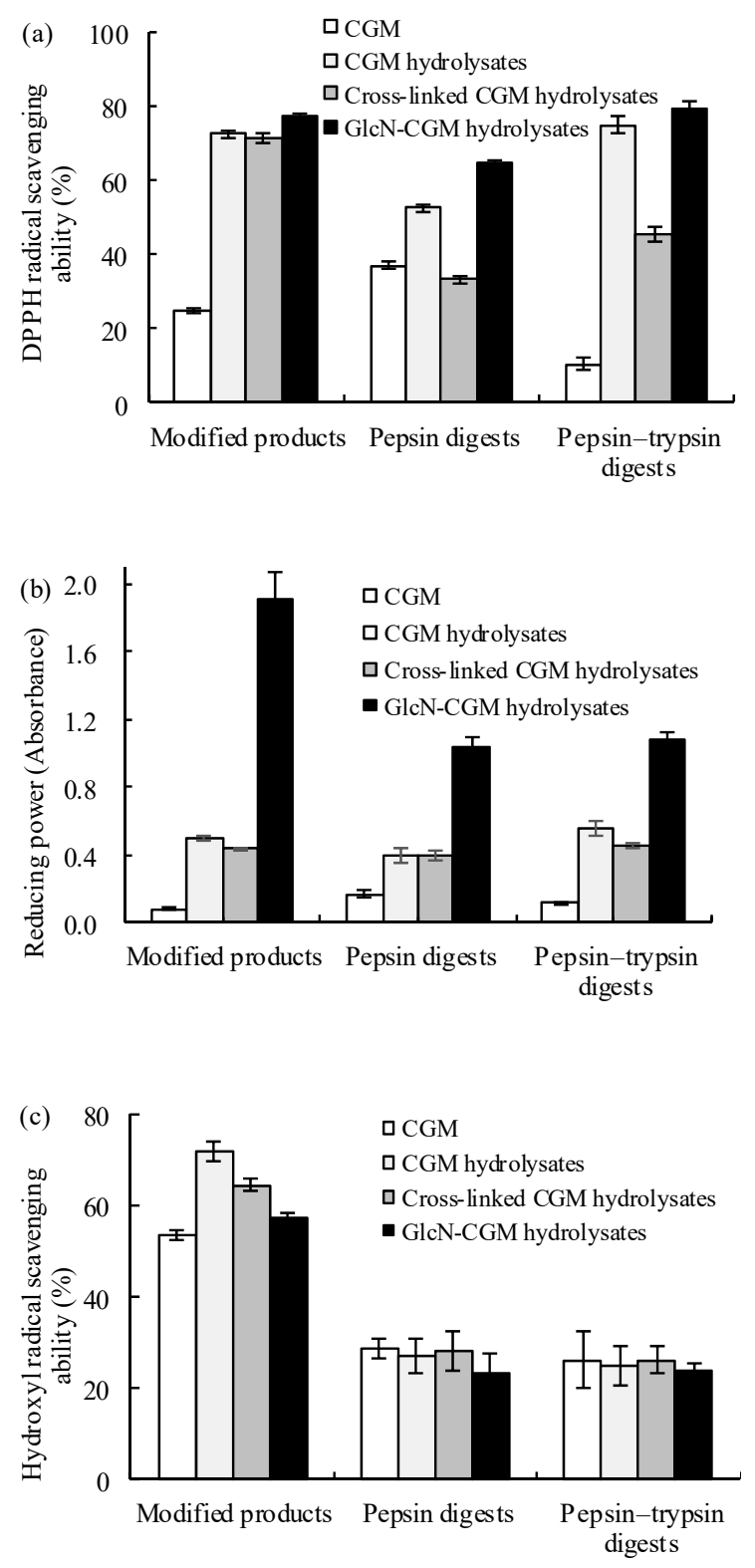

Figure 3. Cont. 


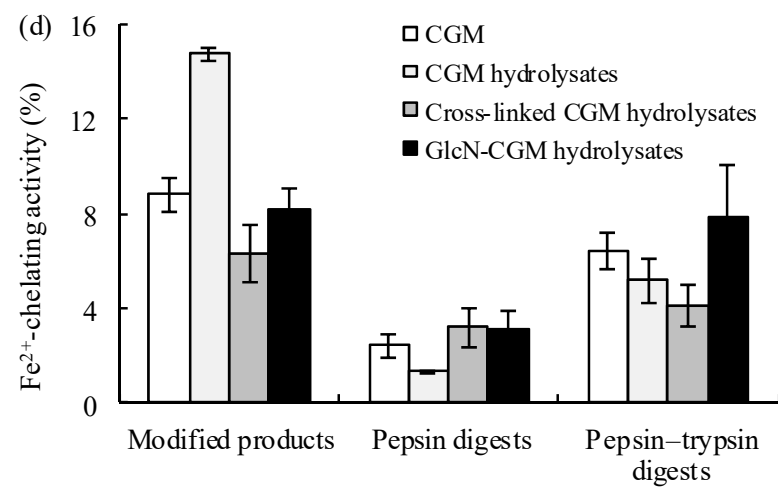

Figure 3. Antioxidant activity of CGM, CGM hydrolysates, cross-linked CGM hydrolysates, GlcN-CGM hydrolysates and their products after being subjected to pepsin and pepsin-trypsin digestions. (a) Diphenylpicrylhydrazyl (DPPH) radical-scavenging activity $(2.0 \mathrm{mg} / \mathrm{mL}),($ b $)$ reducing power $(5.0 \mathrm{mg} / \mathrm{mL})$, (c) hydroxyl radical-scavenging activity $(2.0 \mathrm{mg} / \mathrm{mL})$ and $(\mathbf{d}) \mathrm{Fe}^{2+}$-chelating activity $(2.0 \mathrm{mg} / \mathrm{mL})(n=3$, error bars show standard deviation).

Capacity reduction was used as an indicator of the antioxidant activities of chemicals based on the ability of some reducing substances in the sample to donate electrons or hydrogen ions, thereby resulting in the interruption of free radical chain reactions. The GlcN-CGM hydrolysates had an extremely high reducing capacity, which was significantly increased by about 23-fold and 2.8-fold in comparison with CGM and CGM hydrolysates (1.916 vs. 0.080 and 0.499 ) (Figure 3b). After In Vitro digestion, the digested GlcN-CGM hydrolysates still showed desirable reducing power, although this decreased after peptic or tryptic hydrolysis (Figure $3 b$ ). The enhanced reducing power of the GlcN-conjugated CGM hydrolysates could be explained by the conjugation of GlcN, which can donate electrons or hydrogen ions. It was reported that the glycosylation of CGM with chitosan improved its reducing power [29], thereby supporting our results.

All of the CGM products exhibited good hydroxyl radical-scavenging activities, ranging from $53.5 \%$ to $71.7 \%$ (Figure 3c), which remained (23.1-28.7\%) after being subjected to In Vitro digestion.

The $\mathrm{Fe}^{2+}$-chelating activity of GlcN-conjugated CGM hydrolysates was $8.2 \%$ (Figure 3d). CGM and its hydrolysates exhibited higher $\mathrm{Fe}^{2+}$-chelating activity ( $8.8 \%$ vs. $14.7 \%$ ). A coordination compound was formed between $\mathrm{Fe}^{2+}$ and CGM hydrolysates under $\mathrm{Fe}^{2+}$-chelation, where the hydrogen atoms of the CGM hydrolysate molecules were able to act as ligating atoms. When the saccharide groups were conjugated to the CGM hydrolysates to generate new compounds (GlcN-conjugated CGM hydrolysates), some hydrogen atoms were replaced by polyhydric saccharide groups, thereby reducing their coordinating capability. Consequently, the $\mathrm{Fe}^{2+}$-chelating activity of the GlcN-conjugated CGM hydrolysates decreased. However, the GlcN-CGM hydrolysates had nearly the same $\mathrm{Fe}^{2+}$-chelation activity after being subjected to pepsin and pepsin-trypsin digestions (Figure 3d).

Improved overall antioxidant properties In Vitro in GlcN-CGM hydrolysates were observed, indicating that GlcN-CGM hydrolysates could potentially be used as antioxidant additives in the food industry and related fields. Evaluation of the effect of addition of GlcN-CGM hydrolysates on oxidative stress (intracellular ROS generation) at the cellular level is therefore a meaningful venture.

\subsubsection{Effect of GlcN-CGM Hydrolysate Addition on Cell Viability of LO2 Cells}

The analysis of cell viability, such as through toxicity assays, plays a vital role in all cell culture systems [30]. Cell viability is often defined as the number of healthy cells in a sample, which was used as the index in this experiment. MTT assays were applied to test the cytotoxicity of the GlcN-CGM hydrolysates; the resulting cell viability values are shown in Figure 4. The GlcN-CGM hydrolysates and CGM hydrolysates showed nearly the same or greater cell viability than the control after the cells were incubated at concentrations ranging from 0.05 to $1 \mathrm{mg} / \mathrm{mL}$ for $24 \mathrm{~h}$. LO2 cell pretreatment with GlcN-CGM hydrolysates at a concentration range of $0.75-1 \mathrm{mg} / \mathrm{mL}$ resulted in very high cell viability 
(124.5-132.7\%); therefore, GlcN-CGM hydrolysates and CGM hydrolysates, exhibited a protective effect on hepatocytes to some extent. Gelatin hydrolysates are capable of protecting hepatocytes, according to reports [31]. Moreover, Maillard reaction products form galactose and a gelatin hydrolysate exhibited low cytotoxicity in RAW264.7 cells in comparison with untreated cells [32].

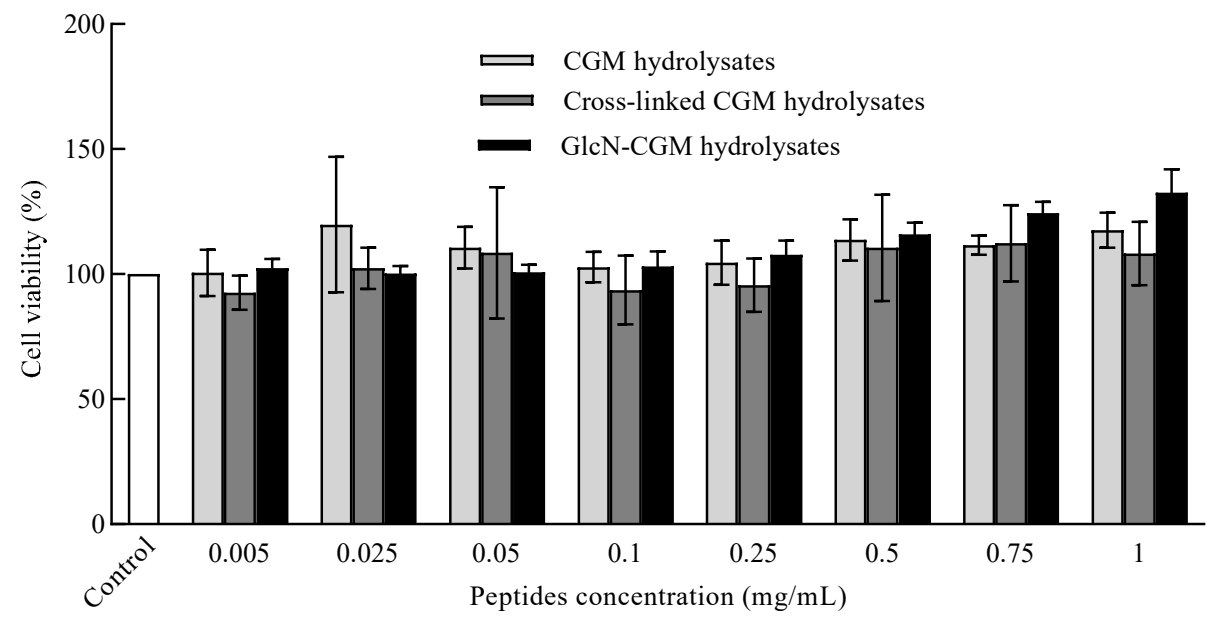

Figure 4. Cell viability assay of CGM hydrolysates, cross-linked CGM hydrolysates and GlcN-CGM hydrolysates at different concentrations in LO2 cells assayed via methyl thiazole tetrazolium (MTT). The values represent the mean $\pm \mathrm{SD}$ of three independent experiments.

\subsubsection{Effect of GlcN-CGM Hydrolysate Addition on Intracellular ROS Generation in LO2 Cells}

ROS play important roles in cellular physiopathology, but excess ROS can impair proteins, lipids and DNA at the cellular level [33]. The detection of intracellular ROS generation is very important, especially when the redox balance of cells is disturbed. DCFH-DA was used as a membrane-permeable probe to detect intracellular ROS [34]. The effects of GlcN-CGM hydrolysates on oxidative stress in LO2 cells caused by exposure to ethanol were measured.

Florescent intensities of stained LO2 cells reflected using a micrograph were used to depict the production of the intracellular ROS of the samples; these results are shown in Figure 5a. Ethanol significantly induced oxidative stress to increase the intracellular ROS generation of LO2 cells and strong florescent intensity was observed. The addition of GlcN-CGM hydrolysates and CGM hydrolysates gradually decreased the intracellular fluorescence intensity and even suppressed it at a concentration of $1 \mathrm{mg} / \mathrm{mL}$. Therefore, GlcN-CGM hydrolysates significantly ameliorated ethanol-induced oxidative damage by reducing intracellular ROS generation. Specifically, the high DCFH-DA fluorescent intensity decreased in a dose-dependent manner with the treatment of GlcN-CGM hydrolysates and CGM hydrolysates (Figure 5b). Markedly decreased intracellular ROS levels of $102.1 \%$ and $107.8 \%$ were observed in GlcN-CGM hydrolysate and CGM hydrolysate experiments under a concentration of $1 \mathrm{mg} / \mathrm{mL}$ for $4 \mathrm{~h}$ after $3 \%(v / v)$ ethanol-induced injury to LO2 cells, which was similar to the control group $(p>0.05)$ (Figure $5 b)$. These results indicate that CGM hydrolysates exhibit protection toward cells, which was consistent with our MTT test results. The added products could alter the environment of the cells [35]; therefore, the ROS production required to oxidize intracellular DCFH to fluorescent DCF in GlcN-CGM hydrolysates was decreased. 
(a)
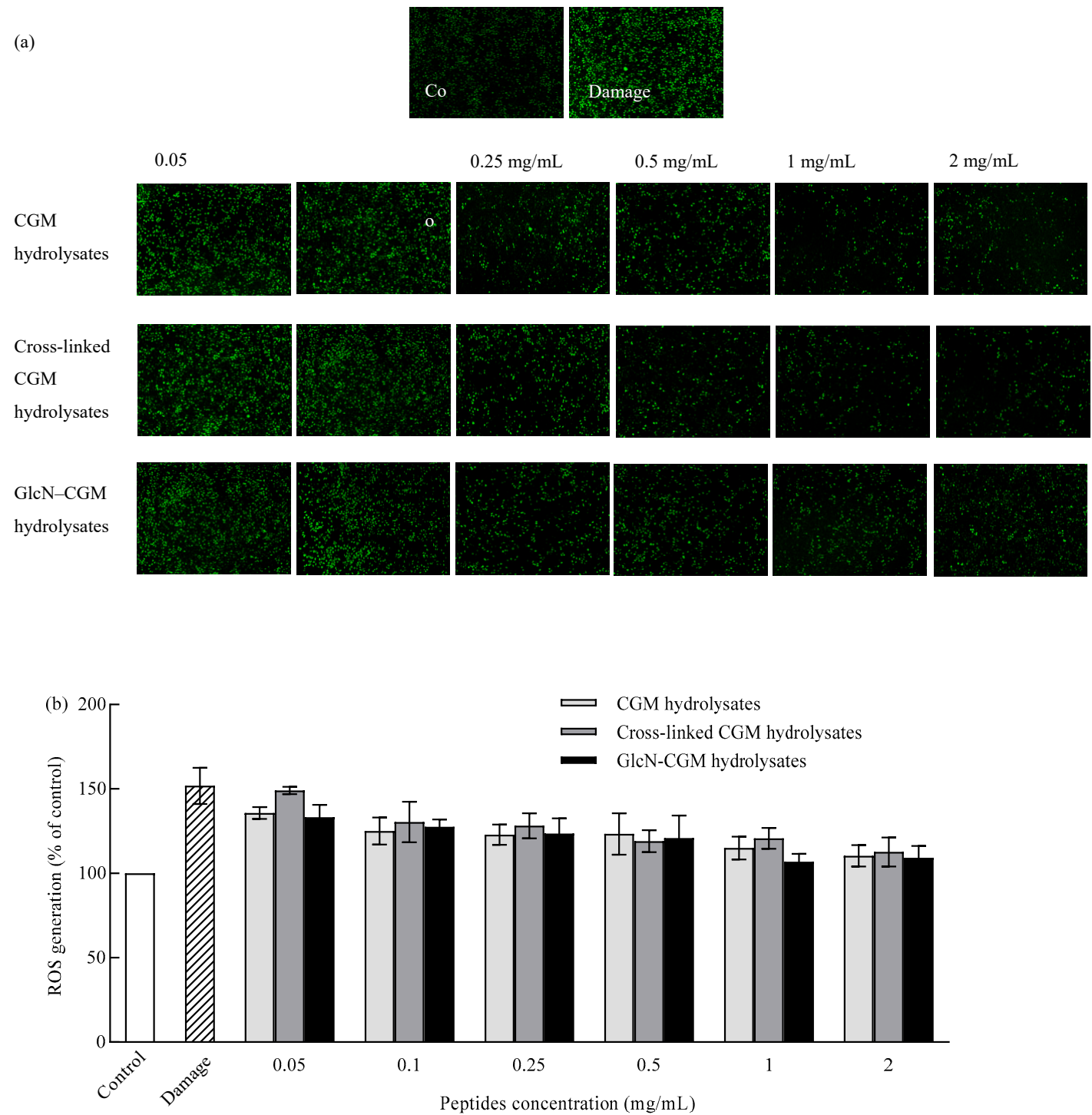

Figure 5. Intracellular reactive oxygen species (ROS) production in LO2 cells pretreated with CGM hydrolysates, cross-linked CGM hydrolysates or GlcN-CGM hydrolysates. (a) Photomicrographs of LO2 cells. Control: cells without any treatment; damage: cells treated with 3\% (v/v) ethanol only. CGM hydrolysates, cross-linked CGM hydrolysates or GlcN-CGM hydrolysates were pretreated with the corresponding CGM hydrolysates samples for $4 \mathrm{~h}$ at 0.05 to $2 \mathrm{mg} / \mathrm{mL}$, followed by $24 \mathrm{~h}$ ethanol exposure at $3 \%(v / v)$. The samples stained with $2^{\prime}, 7^{\prime}$-dichlorofluorescein diacetate (DCFH-DA). (b) Intracellular ROS production values are expressed as the percentage of fluorescence intensity relative to the control. The values are expressed as means \pm SD of at least three independent experiments.

\subsection{Functional Properties of Glycopetides}

\subsubsection{Solubility}

Solubility is a critical criterion for protein functionality [36] and may affect other functional properties, such as emulsification and foaming [37]. The solubility curves of CGM, CGM hydrolysates, cross-linked CGM hydrolysates and GlcN-CGM hydrolysates throughout a pH range of 2-11 are shown in Figure 6. GlcN-CGM hydrolysate solubility majorly increased (74.8-83.2\%) by a much greater proportion than that of CGM (8.3-31.2\%). CGM showed the lowest solubility of all the tested compounds throughout the $\mathrm{pH}$ range, presumably due to its possession of large patches of hydrophobic surface residues [38]. The enhanced solubility of the GlcN-CGM hydrolysates 
was mainly due to the hydrolysis treatment of the CGM, allowing for improved solubility of the CGM hydrolysates (60.5-75.0\%) (Figure 6). In addition, the increased hydroxyl groups provided by the attached saccharides were also partly attributed to the improved solubility of the GlcN-CGM hydrolysates. Moreover, the attached saccharides buried some hydrophobic residues in the interior of the protein molecules. Wang et al. reported that the TGase-catalyzed glycosylation of CGM with GlcN increased its solubility [29]. The high solubility of the GlcN-CGM hydrolysates was not dependent on $\mathrm{pH}$ value, which is a property that could increase their application benefits in the food industry.

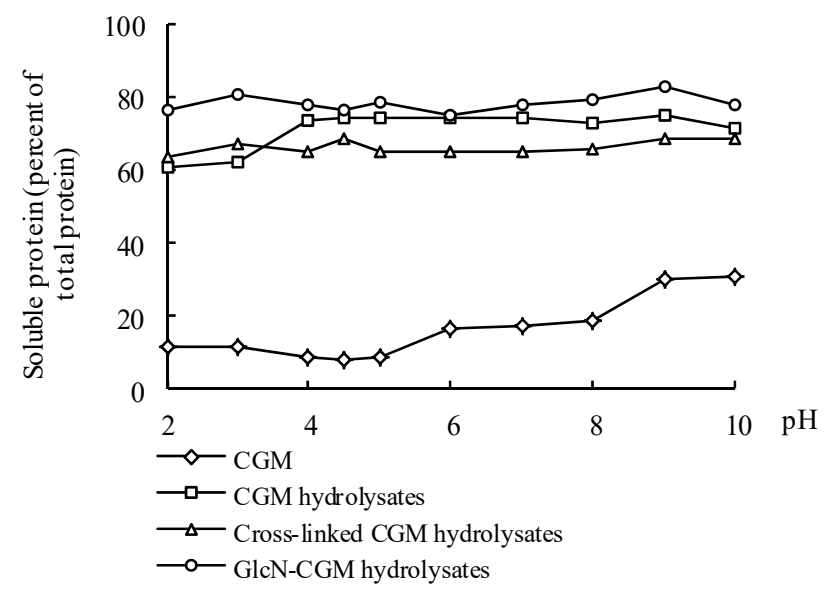

Figure 6. Solubility-pH profiles of CGM, CGM hydrolysates, cross-linked CGM hydrolysates and GlcN-CGM hydrolysates.

\subsubsection{Emulsifying Properties}

Protein emulsification is one of the most important interfacial properties of glycoproteins. The turbidimetric technique is often applied to evaluate emulsification. The emulsifying properties of GlcN-CGM hydrolysates, expressed as EAI and ESI, are shown in Table 1. GlcN-CGM hydrolysates and cross-linked CGM hydrolysates $\left(36.0\right.$ and $57.1 \mathrm{~m}^{2} / \mathrm{g}$ protein) exhibited significantly $(p<0.05)$ higher EAI values than CGM and CGM hydrolysates (28.2 and $28.1 \mathrm{~m}^{2} / \mathrm{g}$ protein, respectively). Meanwhile, the emulsions stabilized by the GlcN-CGM hydrolysates and the cross-linked CGM hydrolysates (74.9 and 70.7\%) showed much higher ESI than the CGM hydrolysates $(63.4 \%)$. The GlcN-conjugated CGM-soybean oil system exhibited higher EAI and ESI values under a $\mathrm{pH}$ of 7 , demonstrating that the oil was able to effectively disperse into the GlcN-CGM hydrolysate solutions while maintaining the stability of the layers between the proteins and lipids. Saccharide (GlcN) conjugation and cross-linking of CGM hydrolysates exhibited positive effects regarding emulsification improvement. On one hand, saccharide groups that adsorbed on the interfacial surface declined the oil-water separation rate, and saccharide $(\mathrm{GlcN})$ conjugation with CGM hydrolysate molecules improved emulsion stability. On the other hand, TGase-mediated cross-linking of proteins gave rise to an increase in negative charges by blocking lysine residues, thereby exhibiting a synergistic effect and enhancing emulsion stability [39].

Table 1. Four evaluated indices of CGM, CGM hydrolysates, cross-linked CGM hydrolysates and GlcN-CGM hydrolysates (mean \pm standard deviation, $n=3$ ).

\begin{tabular}{ccccc}
\hline Functional Property & CGM & $\begin{array}{c}\text { CGM } \\
\text { Hydrolysates }\end{array}$ & $\begin{array}{c}\text { Cross-linked CGM } \\
\text { Hydrolysates }\end{array}$ & $\begin{array}{c}\text { GlcN-CGM } \\
\text { Hydrolysates }\end{array}$ \\
\hline Glucosamine (g/kg protein) & 0 & 0 & 0 & $23.0 \pm 0.11$ \\
Surface hydrophobicity & $8.1 \pm 0.45^{\mathrm{a}}$ & $28.1 \pm 0.85^{\mathrm{d}}$ & $20.4 \pm 1.49^{\mathrm{c}}$ & $16.3 \pm 0.77^{\mathrm{b}}$ \\
Emulsifying activity index (m ${ }^{2} / \mathrm{g}$ protein) & $28.2 \pm 1.2^{\mathrm{a}}$ & $28.1 \pm 2.2^{\mathrm{a}}$ & $57.1 \pm 3.4^{\mathrm{c}}$ & $36.0 \pm 2.3^{\mathrm{b}}$ \\
Emulsion stability index (\%) & $39.0 \pm 2.2^{\mathrm{a}}$ & $63.4 \pm 4.2^{\mathrm{b}}$ & $70.7 \pm 2.8^{\mathrm{c}}$ & $74.9 \pm 1.9^{\mathrm{d}}$ \\
\hline
\end{tabular}

Different lowercase letters represent the superscripts after the values in same row indicate that one-way ANOVA of the means is significantly different $(p<0.05)$. 


\subsubsection{Surface Hydrophobicity}

Surface hydrophobicity is also a vital functional property regarding the stabilization of food protein intermolecular structures. The more distributed the aromatic and aliphatic amino acid residues on protein surfaces are, the greater the surface hydrophobicity. The surface hydrophobicity of the GlcN-CGM hydrolysates is shown in Table 1. The GlcN-CGM hydrolysates presented a lower surface hydrophobicity index (16.3) than the CGM hydrolysates and cross-linked CGM hydrolysates (28.1 and 20.4), but a value higher than CGM (8.1), indicating that ANS probes did not easily bind the hydrophobic regions of CGM. A high surface hydrophobicity in the CGM hydrolysates was observed because a flexible exposure high ratio of the hydrophobic amino acids surface zones (Ala of $6.89 \%$, Val of $5.70 \%$, Leu of $11.39 \%$, etc.) occurred during hydrolysis. However, GlcN conjugation and the cross-linking of CGM hydrolysates decreased surface hydrophobicity. TGase catalyzed the glycosylation between the saccharide moieties and $\beta$-lactoglobulin [40], or the cross-linking of whey proteins [41] and a decrease in overall surface hydrophobicity.

\section{Conclusions}

New GlcN-conjugated CGM hydrolysates (glycopeptides) were successfully produced by TGase-mediated glycosylation between CGM hydrolysates and GlcN. The glycosylation of CGM could enhance its antioxidant activities and reveal functional properties that are not found in the natural form. The strategy adopted in the present study could open up new economic opportunities for CGM utilization, allowing new glycopeptides from CGM to be applied as additives to certain functional foods.

Author Contributions: X.-L.L. writing—reviewing and editing; C.-L.S. writing-original draft; J.-P.C. performed the experiments and analyzed the data; X.L. performed the experiments and analyzed the data; J.R. analyzed the experimental data; X.-Q.Z. experimental design and funding acquisition. All authors have read and agreed to the published version of the manuscript.

Funding: This research was funded by the national Key Research and Development Plan of China (No. 2017YFD0400200), National Natural Science Foundation of China (No. 31371726), Natural Science Foundation of Heilongjiang Province of China (No. ZD2016005), and Heilongjiang Provincial Education Department of China (No. LTSW201725 and 135209104), Heilongjiang Provincial Foundation for the Characteristic Discipline of Processing Technology of Plant Foods (No. YSTSXK201803).

Conflicts of Interest: The authors declare no conflict of interest.

\section{Abbreviations}

$\begin{array}{ll}\text { CGM } & \text { Corn gluten meal } \\ \text { GlcN } & \text { Glucosamine } \\ \text { TGase } & \text { Transglutaminase } \\ \text { HPLC } & \text { High performance liquid chromatography } \\ \text { FTIR } & \text { Fourier transform infrared spectroscopy } \\ \text { ESI-TOF MS/MS } & \text { Electrospray ionisation-time-of-flight mass spectrometry }\end{array}$

\section{References}

1. National bureau of statistics of China. Corn Yield Statistics Reports for the China. 2019. Available online: http://data.stats.gov.cn/search.htm?s/aboutChinacorn/statistics/Chinacornstatsreport (accessed on 26 April 2020).

2. Park, P.J.; Jung, W.K.; Nam, K.S.; Shahidi, F.; Kim, S.K. Purification and characterization of antioxidative peptides from protein hydrolysate of lecithin-free egg yolk. J. Am. Oil Chem. Soc. 2001, 78, 651-656. [CrossRef]

3. Landry, J.; Delhaye, S.; di Gioia, L. Protein distribution in gluten products isolated during and after wet-milling of maize grains. Cereal Chem. 1999, 76, 503-505. [CrossRef]

4. Shukla, R.; Cheryan, M. Zein: The industrial protein from corn. Ind. Crop. Prod. 2001, 13, 171-192. [CrossRef] 
5. Smith, R.J.; Wilmore, D.W. Glutamine nutrition and requirements. JPEN-Parenter. Enter. 1990, 14, 94S-99S. [CrossRef]

6. Wang, L.; Yu, B.; Wang, R.; Xie, J. Biotechnological routes for transglutaminase production: Recent achievements, perspectives and limits. Trends Food Sci. Technol. 2018, 81, 116-120. [CrossRef]

7. Colas, B.; Caer, D.; Fournier, E. Transglutaminase-catalyzed glycosylation of vegetable proteins. Effect on solubility of pea legumin and wheat gliadins. J. Agric. Food Chem. 1993, 41, 1811-1815. [CrossRef]

8. Shi, J.; Zhao, X.H. In Vitro immuno-modulatory ability of tryptic caseinate hydrolysate affected by prior caseinate glycation using the Maillard reaction or transglutaminase. Food Agric. Immunol. 2017, 28, 1029-1045. [CrossRef]

9. Hong, P.K.; Gottardi, D.; Ndagijimana, M.; Betti, M. Glycation and transglutaminase mediated glycosylation of fish gelatin peptides with glucosamine enhance bioactivity. Food Chem. 2014, 142, 285-293. [CrossRef]

10. Kieliszek, M.; Misiewicz, A. Microbial transglutaminase and its application in the food industry. A review. Folia Microbiol. 2014, 59, 241-250. [CrossRef]

11. Mattei, G.; Cacopardo, L.; Ahluwalia, A. Engineering gels with time-evolving viscoelasticity. Materials 2020, 13, 14. [CrossRef]

12. Zheng, X.Q.; Liu, X.L.; Yu, S.F.; Wang, X.J.; Ma, Y.Q.; Yang, S.; Jing, S.S. Effects of extrusion and starch removal pretreatment on zein proteins extracted from corn gluten meal. Cereal Chem. 2014, 91, 496-501. [CrossRef]

13. Adler-Nissen, J. Limited enzymic degradation of proteins: A new approach in the industrial application of hydrolases. J. Chem. Technol. Biotechnol. 1982, 32, 138-156. [CrossRef]

14. El-Saharty, Y.S.; Bary, A.A. High-performance liquid chromatographic determination of neutraceuticals, glucosamine sulphate and chitosan, in raw materials and dosage forms. Anal. Chim. Acta 2002, 462, 125-131. [CrossRef]

15. Anumula, K. Quantitative determination of monosaccharides in glycoproteins by high-performance liquid chromatography with highly sensitive fluorescence detection. Anal. Biochem. 1994, 220, 275-283. [CrossRef] [PubMed]

16. Zheng, X.Q.; Wang, J.T.; Liu, X.L.; Sun, Y.; Zheng, Y.J.; Wang, X.J.; Liu, Y. Effect of hydrolysis time on the physicochemical and functional properties of corn glutelin by Protamex hydrolysis. Food Chem. 2015, 172, 407-415. [CrossRef] [PubMed]

17. Marciniak-Darmochwal, K.; Kostyra, H. Influence of nonenzymatic glycosylation (glycation) of pea proteins (Pisum sativum) on their susceptibility to enzymatic hydrolysis. J. Food Biochem. 2009, 33, 506-521. [CrossRef]

18. Tang, C.H.; Sun, X.; Yin, S.W.; Ma, C.Y. Transglutaminase-induced cross-linking of vicilin-rich kidney protein isolate: Influence on the functional properties and In Vitro digestibility. Food Res. Int. 2008, 41, 941-947. [CrossRef]

19. Choe, I.H.; Jeon, H.J.; Eom, S.H.; Han, Y.K.; Kim, Y.S.; Lee, S.H. The anti-inflammatory effect of a glycosylation product derived from the high hydrostatic pressure enzymatic hydrolysate of a flatfish byproduct. Food Funct. 2016, 7, 2557-2565. [CrossRef]

20. Vieira, E.F.; da Silva, D.D.; Carmo, H.; Ferreira, I.M. Protective ability against oxidative stress of brewers' spent grain protein hydrolysates. Food Chem. 2017, 228, 602-609. [CrossRef]

21. Bera, M.; Mukherjee, R. Solubility, emulsifying, and foaming properties of rice bran protein concentrates. J. Food Sci. 1989, 54, 142-145. [CrossRef]

22. Pearce, K.N.; Kinsella, J.E. Emulsifying properties of proteins: Evaluation of a turbidimetric technique. J. Agric. Food Chem. 1978, 26, 716-723. [CrossRef]

23. Hayakawa, S.; Nakai, S. Relationships of hydrophobicity and net charge to the solubility of milk and soy proteins. J. Food Sci. 1985, 50, 486-491. [CrossRef]

24. Jiang, S.J.; Zhao, X.H. Transglutaminase-induced cross-linking and glucosamine conjugation of casein and some functional properties of the modified product. Int. Dairy J. 2011, 21, 198-205. [CrossRef]

25. Jiang, S.J.; Zhao, X.H. Transglutaminase-induced cross-linking and glucosamine conjugation in soybean protein isolates and its impacts on some functional properties of the products. Eur. Food Res. Technol. 2010, 231, 679-689. [CrossRef]

26. Guan, J.J.; Qiu, A.Y.; Liu, X.Y.; Hua, Y.F.; Ma, Y.H. Microwave improvement of soy protein isolate-saccharide graft reactions. Food Chem. 2006, 97, 577-585. [CrossRef] 
27. Lu, R.R.; Qian, P.; Sun, Z.; Zhou, X.H.; Chen, T.P.; He, J.F.; Zhang, H.; Wu, J. Hempseed protein derived antioxidative peptides: Purification, identification and protection from hydrogen peroxide-induced apoptosis in PC12 cells. Food Chem. 2010, 123, 1210-1218. [CrossRef]

28. Gottardi, D.; Hong, P.K.; Ndagijimana, M.; Betti, M. Conjugation of gluten hydrolysates with glucosamine at mild temperatures enhances antioxidant and antimicrobial properties. LWT-Food Sci. Technol. 2014, 57, 181-187. [CrossRef]

29. Wang, X.J.; Zheng, X.Q.; Liu, X.L.; Kopparapu, N.K.; Cong, W.S.; Deng, Y.P. Preparation of glycosylated zein and retarding effect on lipid oxidation of ground pork. Food Chem. 2017, 227, 335-341. [CrossRef]

30. Stoddart, M.J. Cell viability assays: Introduction. In Mammalian Cell Viability; Springer: Berlin, Germany, 2011; pp. 1-6.

31. Fu, Y.; Zhao, X.H. Utilization of chum salmon (Oncorhynchus keta) skin gelatin hydrolysates to attenuate hydrogen peroxide-induced oxidative injury in rat hepatocyte BRL cell model. J. Aquat. Food Prod. Technol. 2015, 24, 648-660. [CrossRef]

32. Karnjanapratum, S.; O'Callaghan, Y.C.; Benjakul, S.; O’Brien, N.M. In Vitro cellular bioactivities of Maillard reaction products from sugar-gelatin hydrolysate of unicorn leatherjacket skin system. J. Funct. Foods 2016, 23, 87-94. [CrossRef]

33. Ameziane-El-Hassani, R.; Dupuy, C. Detection of Intracellular Reactive Oxygen Species (CM-H2DCFDA). Bio-protocol 2013, 3, e313. [CrossRef]

34. Zhang, Q.; Tong, X.; Qi, B.; Wang, Z.; Li, Y.; Sui, X.; Jiang, L. Changes in antioxidant activity of Alcalase-hydrolyzed soybean hydrolysate under simulated gastrointestinal digestion and transepithelial transport. J. Funct. Foods 2018, 42, 298-305. [CrossRef]

35. Barzegar, A.; Moosavi-Movahedi, A.A. Intracellular ROS protection efficiency and free radical-scavenging activity of curcumin. PLoS ONE 2011, 6, e26012. [CrossRef] [PubMed]

36. Kinsella, J.E.; Melachouris, N. Functional properties of proteins in foods: A survey. Crit. Rev. Food Sci. Nutr. 1976, 7, 219-280. [CrossRef]

37. Hettiarachchy, N.; Griffin, V.; Gnanasambandam, R. Reparation and functional properties of a protein isolate from defatted wheat germ. Cereal Chem. 1996, 73, 364-367.

38. Yong, Y.H.; Yamaguchi, S.; Gu, Y.S.; Mori, T.; Matsumura, Y. Effects of enzymatic deamidation by protein-glutaminase on structure and functional properties of $\alpha$-zein. J. Agric. Food Chem. 2004, 52, 7094-7100. [CrossRef]

39. Agyare, K.K.; Addo, K.; Xiong, Y.L. Emulsifying and foaming properties of transglutaminase-treated wheat gluten hydrolysate as influenced by $\mathrm{pH}$, temperature and salt. Food Hydrocoll. 2009, 23, 72-81. [CrossRef]

40. Van Teeffelen, A.M.; Broersen, K.; de Jongh, H.H. Glucosylation of $\beta$-lactoglobulin lowers the heat capacity change of unfolding; a unique way to affect protein thermodynamics. Protein Sci. 2005, 14, 2187-2194. [CrossRef]

41. Agyare, K.K.; Damodaran, S. pH-stability and thermal properties of microbial transglutaminase-treated whey protein isolate. J. Agric. Food Chem. 2010, 58, 1946-1953. [CrossRef]

(C) 2020 by the authors. Licensee MDPI, Basel, Switzerland. This article is an open access article distributed under the terms and conditions of the Creative Commons Attribution (CC BY) license (http://creativecommons.org/licenses/by/4.0/). 